\title{
Redox reactivity at silver microparticle — glassy carbon contacts under a coating of polymer of intrinsic microporosity (PIM)
}

\author{
Daping $\mathrm{He}^{1} \cdot$ Erwan Rauwel $^{2} \cdot$ Richard Malpass-Evans $^{3} \cdot$ Mariolino Carta $^{3}$. \\ Neil B. McKeown ${ }^{3}$ • Demudu Babu Gorle ${ }^{4}$ - M. Anbu Kulandainathan ${ }^{4}$. \\ Frank Marken ${ }^{1}$
}

Received: 4 December 2016 / Revised: 4 February 2017 / Accepted: 7 February 2017 / Published online: 16 February 2017

(C) The Author(s) 2017. This article is published with open access at Springerlink.com

\begin{abstract}
Silver microparticles (ca. $1 \mu \mathrm{m}$ average size clustered into cage-like aggregates of $10-20 \mu \mathrm{m}$ diameter) are shown to adhere to a glassy carbon electrode surface to give voltammetric current responses, which are considerably enhanced/stabilised when applying a coating with a molecularly rigid polymer of intrinsic microporosity (PIM-EA-TB). In preliminary voltammetric experiments characteristic $\mathrm{Ag}(0 / \mathrm{I})$ surface oxidation and back-reduction processes are observed in aqueous phosphate buffer (associated with silver phosphate layer formation on the silver surface). In contrast to the oxidation, which is dominated by a nucleation process causing a sharp well-defined current signal, for the back-reduction stochastic current responses are observed possibly associated with density fluctuations in the surrounding liquid phase ("Brownian activation") as an essential part of the mechanism of conversion of surface-oxidised silver back to silver metal.
\end{abstract}

Keywords Microparticle $\cdot$ Polymer membrane $\cdot$ Brownian motion $\cdot$ Stochastic $\cdot$ Catalysis

To be communicated to Journal of Solid State Electrochemistry

Frank Marken

f.marken@bath.ac.uk

1 Department of Chemistry, University of Bath, Claverton Down, Bath BA2 7AY, UK

2 Tartu College, Tallinn University of Technology, Puiestee 78, 51008 Tartu, Estonia

3 School of Chemistry, University of Edinburgh, West Mains Road, Edinburgh EH9 3JJ, UK

4 Electro-organic Division, Central Electrochemical Research Institute, Karaikudi, Tamil-Nadu 630-006, India

\section{Introduction}

Voltammetric analysis of microparticles [1] has been developed as analytical tool in the study of redox-active materials which are "mechanically attached" [2] or adhered [3] or simply deposited from solution onto suitable electrode surfaces. For silverbased materials, voltammetric microparticle analysis has been applied to silver tarnish products [4]and silver alloys [5]. In recent work on silver nanoparticle electrochemistry in solution, the "impact" of these nanoparticles [6] and the resulting redox conversion [7] were employed to obtain nanoparticle size, shape [8], and reactivity [9] information. Due to the small size of these nanoparticles (and the appropriate choice of reaction conditions) complete/quantitative conversion of silver to soluble or insoluble species is usually possible [10]. In contrast, for macroscopic silver samples, for example a silver wire or silvercoated textiles, in contact to a glassy carbon electrode surface [11], more complex behaviour has been reported with incomplete conversion and formation of an electrically insulating layer between silver metal and electrode surface. The electrical contact of metallic silver to the underlying glassy carbon electrode has been shown to be broken during oxidation when an insulating film is produced. As a result, only a small amount of the available silver was oxidised [11]. The back-reduction to metallic silver was suggested to be associated with nucleation of silver metal on glassy carbon and a "re-connection" from glassy carbon to the metallic silver-coated textile. Very similar processes are observed here for silver microparticles immobilised at a glassy carbon electrode surface and immersed in aqueous electrolyte media.

An intrinsically microporous polymer coating is introduced to improve the microparticle voltammetry experiment by avoiding microparticle loss or dislodgement during immersion or during potential cycling. This can be crucial for example for application in electrocatalysis where microparticles 
have to remain in contact to the electrode surface. Microparticles have to withstand significant mechanical forces during wetting (during immersion) and during drying (for re-use). Figure 1 shows a schematic drawing of a silver microparticle immobilised at a glassy carbon electrode surface. When in the reduced form, the metallic silver makes electrical contact to the glassy carbon. However, when oxidised, the silver is coated with an insulator and electrically disconnected. The silver microparticles are studied here when mechanically "fixed" by application of an intrinsically microporous polymer (see PIM-EA-TB in Fig. 1b).

The application of a polymer of intrinsic microporosity (PIM) as new class of molecularly rigid and microporous ion-conducting materials in electrochemistry has been suggested recently [12]. It has been demonstrated that metal nanoparticle catalysts can be PIM-coated and thereby protected against poisoning [13] and against detrimental loss and corrosion processes [14]. Here, we employ an intrinsically microporous polymer (PIM) material based on an ethanoanthracene (EA) building block that was synthesised employing a Tröger base (TB) method (PIM-EA-TB [15], see molecular structure in Fig. 1b). This polymer material exhibits $70 \mathrm{kDa}$ average molecular weight and $\mathrm{N}_{2}$-adsorption surface area of typically $1027 \mathrm{~m}^{2} \mathrm{~g}^{-1}$ [15]. The inherent microporosity of PIM-EA-TB allows ion and small molecule transport without inhibiting the electrode reaction [16]. The rigid molecular structure ensures a stable attachment of the microparticles to the electrode surface as well as sufficient access of electrolyte through the microporous film.

In this study, silver microparticles are investigated at glassy carbon electrode surfaces and when immersed into aqueous phosphate buffer solution. During oxidation, silver microparticles are shown to only react partially (similar to silver wire in contact to glassy carbon [11]) due to surface coating with an insulating silver phosphate film. The process is chemically reversible, and after back reduction, the silver microparticles remain at the electrode surface (protected by a PIM-EA-TB film). Stochastic events during the reduction are suggested to be associated with activation by interfacial momentum transfer from Brownian motion in the liquid phase.

\section{Experimental}

Chemical reagents Chloroform, isopropanol, sodium hydroxide, and phosphoric acid (85\%) were purchased from Aldrich and used without further purification. PIM-EA-TB was prepared following a literature recipe [17]. Solutions were prepared with filtered and deionised water of resistivity $18.2 \mathrm{M} \Omega \mathrm{cm}$ from a Thermo Scientific water purification system (ELGA).

Instrumentation A $\mu$ Autolab III system (Ecochemie, NL) was employed for electrochemical measurements in a
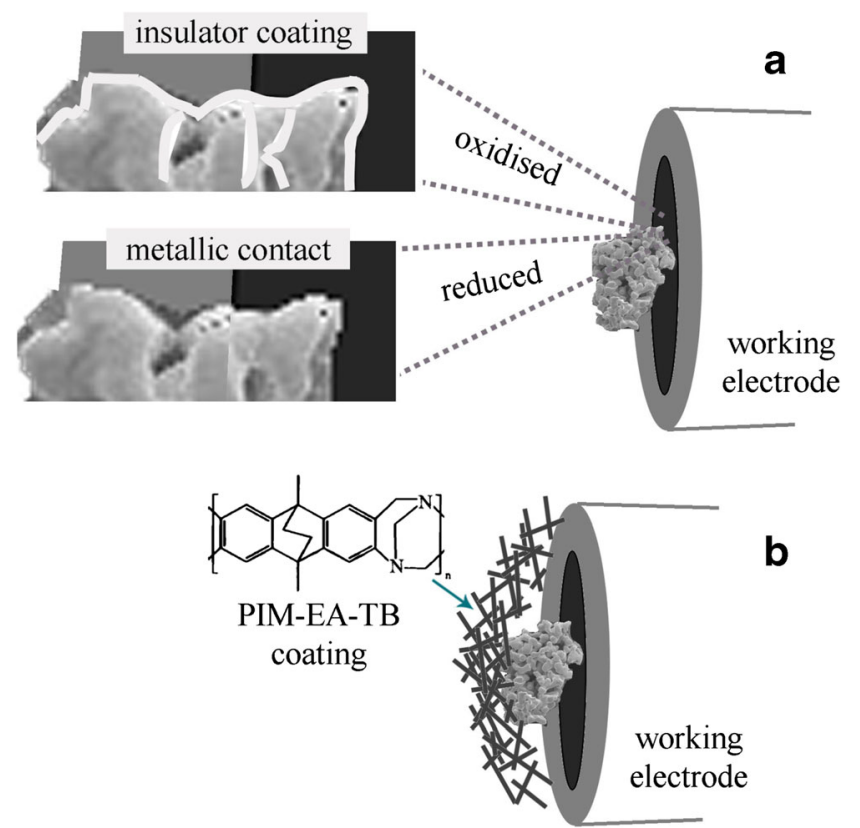

Fig. 1 a Schematic drawing of silver microparticles deposited onto a working electrode with (i) oxidation leading to formation of an insulating coating and (ii) back-reduction restoring the metallic electrode - silver contact. b Molecular structure of the polymer of intrinsic microporosity PIM-EA-TB that was used to coat and stabilise the silver microparticle-electrode contact

conventional three-electrode cell with a platinum wire counter electrode and a $\mathrm{KCl}$-saturated calomel (SCE) reference (Radiometer, Kopenhagen). All experiments were performed with a 3-mm-diameter glassy carbon electrode (Bioanalytical Systems, IN, USA). Morphology of the silver sample was analysed with a JEOL FESEM6301F scanning electron microscope (SEM).

Silver microparticles synthesis The synthesis of Ag microparticles is based on the non-hydrolytic sol-gel method [18,19] that has been recently applied for the synthesis of Ag antimicrobial coatings [20, 21]. Briefly, $642 \mathrm{mg}$ of silver acetate (99\%, Aldrich) along with $20 \mathrm{~cm}^{3}$ of benzylamine (99\%, Aldrich) were used for the synthesis of the particles. The result mixture was transferred into a stainless steel autoclave and heated at $200{ }^{\circ} \mathrm{C}$ for $48 \mathrm{~h}$. The resulting suspension was centrifuged and the silver microparticles separated as precipitate, thoroughly washed with ethanol, and subsequently dried in air at $70^{\circ} \mathrm{C}$.

Procedures for electrode preparation Electrodes were prepared by drop casting. A weight of $4 \mathrm{mg}$ of $\mathrm{Ag}$ microparticles was dispersed in $1 \mathrm{~mL}$ of isopropanol. After sonication for $15 \mathrm{~min}$, the prepared suspension was loaded onto a glassy carbon (GC) disk electrode with a diameter of $3 \mathrm{~mm}$. The silver layer was allowed to dry under ambient conditions before electrochemical measurements. The PIM-Ag samples were prepared by coatings with PIM-EA-TB on Ag. A 
solution of $1 \mathrm{mg} \mathrm{mL}^{-1}$ PIM-EA-TB in chloroform was applied directly onto the Ag microparticle layer followed by drying under ambient conditions.

\section{Results and discussion}

Initial experiments were performed with $2 \mu \mathrm{g}$ silver microparticles (previously synthesised for application as antimicrobial agent [20, 21], see Fig. 2) drop-cast deposited onto a glassy carbon electrode surface and immersed in aqueous $0.1 \mathrm{M}$ phosphate buffer $\mathrm{pH}$ 12. Figure 3 a shows voltammograms with an oxidation response at $0.26 \mathrm{~V}$ vs. SCE. Silver has been reported to undergo oxidation (anodic dissolution) in neutral aqueous phosphate buffer media to switch from $\operatorname{Ag}(0)$ to $\mathrm{Ag}(\mathrm{I})$ accompanied by formation of poorly soluble phosphate films [11, 22, 23] (see Eq. 1). This equation is here tentatively assigned to the process observed in Fig. 3, although the true chemical nature of " $\mathrm{Ag}_{3} \mathrm{PO}_{4}(\mathrm{~s})$ " under these conditions may be more complicated.

$3 \mathrm{Ag}(\mathrm{m})+\mathrm{HPO}_{4}{ }^{2-}(\mathrm{aq}) \rightleftarrows \mathrm{Ag}_{3} \mathrm{PO}_{4}(\mathrm{~s})+\mathrm{H}^{+}(\mathrm{aq})+3 e^{-}$
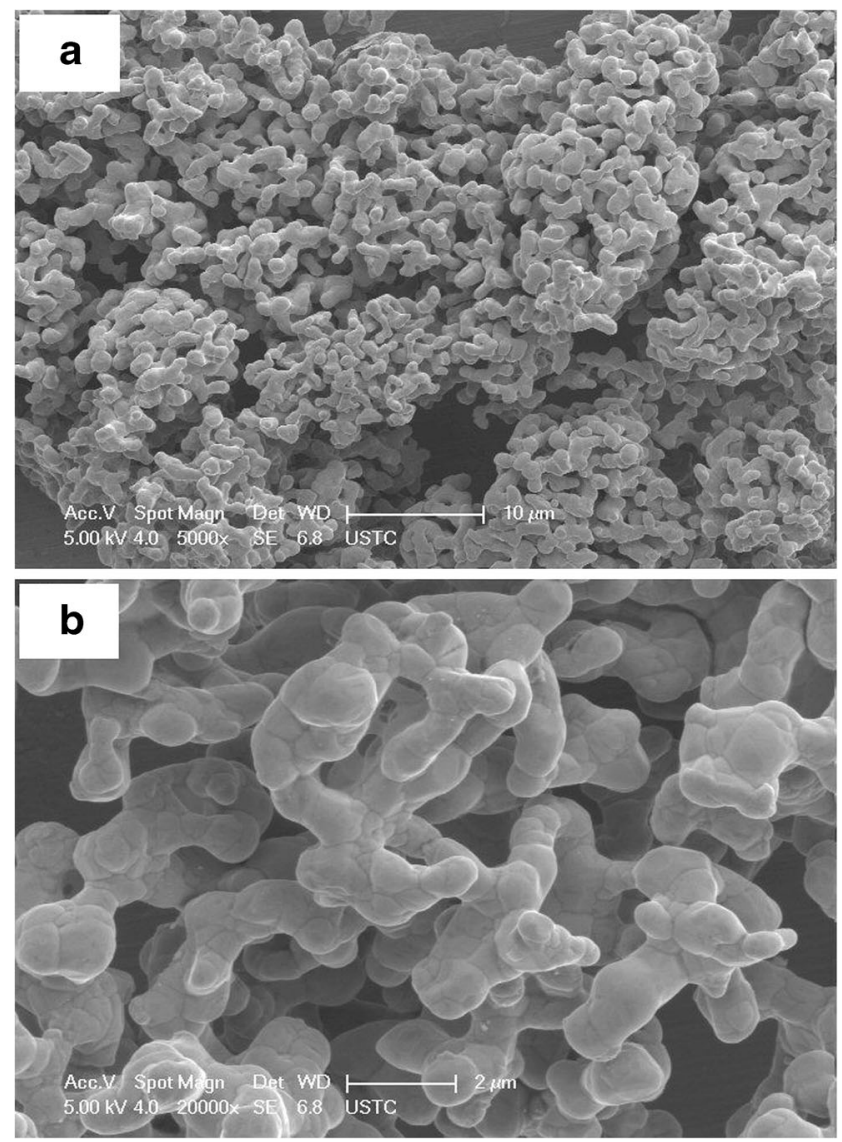

Fig. 2 Scanning electron micrographs at a lower $(\times 5000)$ and $\mathbf{b}$ higher $(\times 20000)$ magnification showing silver microparticle aggregates
The area under the oxidation peak suggests approximately $5 \mu \mathrm{C}$ charge has passed, which corresponds to only $0.2 \%$ of the silver present. When applying a film of $4 \mu \mathrm{g}$ PIM-EA-TB from a chloroform solution over the silver microparticles on the glassy carbon surface, the oxidation signal in the voltammogram can be improved by one order of magnitude in terms of charge (see Fig. 3a). The PIM-EA-TB polymer is proposed to act here as a porous matrix that allows oxidation and reduction to occur whilst stopping losses due to dislodged silver microparticles. As a result, voltammetric responses for the silver microparticles are more stable and repeatable. Within the potential range studied here PIM-EA-TB has no direct electrochemical activity $[13,14]$ and it can be considered both cation and anion conducting [15]. Generally, with the PIMEA-TB coating applied features such as the position of oxidation and back-reduction voltammetric responses are maintained and also the complex peak shape observed during the reduction is retained. Figure $3 \mathrm{~b}$ shows how the amount of
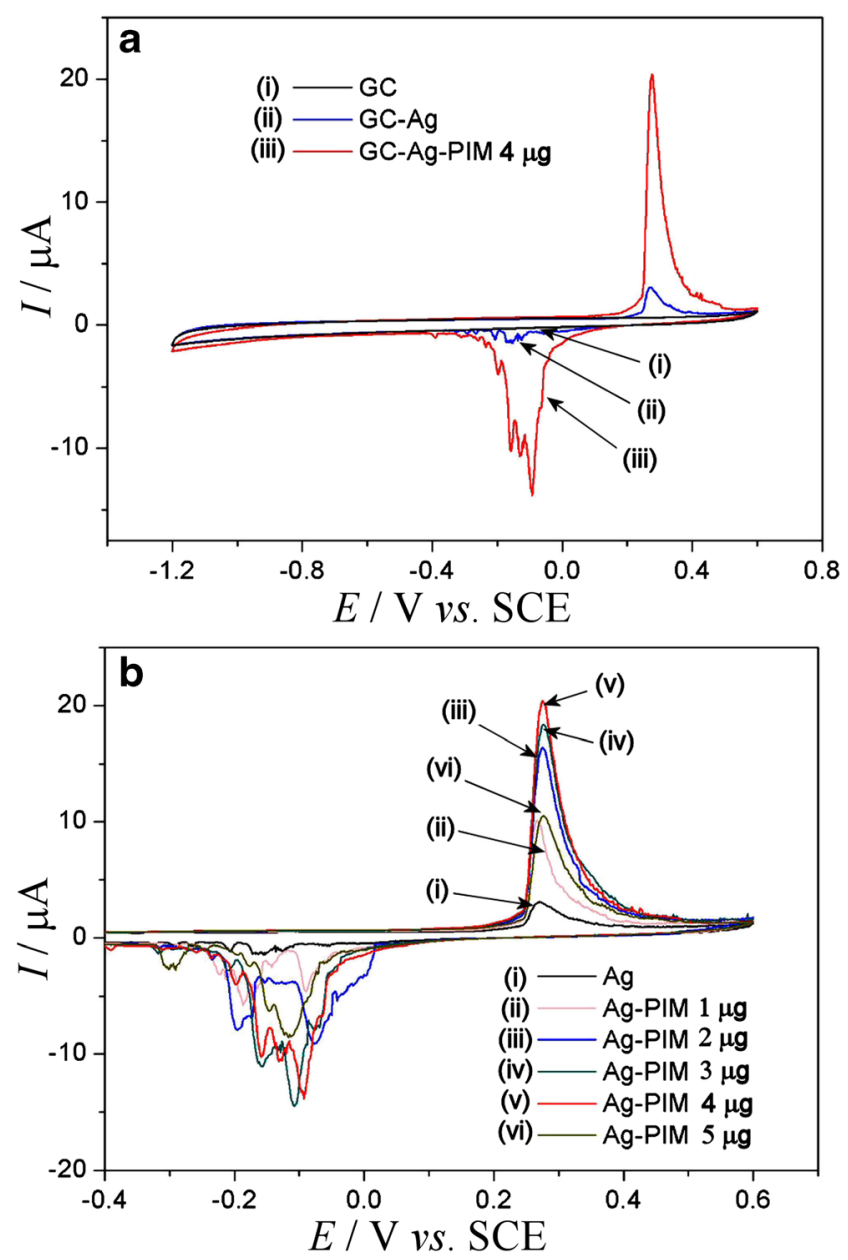

Fig. 3 a Cyclic voltammograms (scan rate $50 \mathrm{mVs}^{-1}$ ) for a micro-silver deposit on glassy carbon immersed in aqueous $0.1 \mathrm{M}$ PBS pH 12 for (i) the bare glassy carbon, (ii) $2 \mu \mathrm{g}$ micro-silver on glassy carbon, and (iii) with a $4 \mu \mathrm{g}$ PIM film applied. b As above, but with different Ag to PIM ratios 
PIM-EA-TB deposited over the electrode surface affects the voltammetric responses. With approximately $4 \mu \mathrm{g}$ polymer, a relatively stable/repeatable signal is obtained. Excess PIMEA-TB leads to lowering of current responses. Therefore, in the following experiments, this amount of $4 \mu \mathrm{g}$ polymer coating is kept constant.

Figure $4 \mathrm{a}$ demonstrates the effect of the amount of silver microparticles on voltammetric responses. The magnitude of both oxidation and back-reduction signals increases with the amount of silver deposited. This as well as the change in capacitive background current suggests that the silver microparticles are well connected in the potential range negative of the oxidation process. However, the trend is non-linear and possibly connected to factors such as packing of silver microparticles and importantly the ratio of Ag to PIM. When changing the potential scan rate (Fig. 4b), more complex behaviour is observed. The anodic process results in the very sharp increase in the current at $0.26 \mathrm{~V}$ vs. SCE independent of the scan rate, which is believed to be associated with a nucleation of silver phosphate (eq. 1) on the silver surface. Upon scanning the potential negative the reduction peak appears complex and random without well-defined peak potential and/or onset potential. With increased scan rate, peaks move in average to more negative potentials. When adding nitrate into the solution (Fig. 4c), the well-known silver-catalysed two-electron reduction of nitrate to nitrite (Eq. 2 [24, 25]) is observed.

$\mathrm{NO}_{2}-(\mathrm{aq})+\mathrm{OH}^{-}(\mathrm{aq}) \rightleftarrows \mathrm{NO}_{3}^{-}(\mathrm{aq})+\mathrm{H}^{+}(\mathrm{aq}) 2 e^{-}$

The limiting current for the catalytic nitrate reduction is approximately linear to the nitrate concentration in the 1 to $100 \mathrm{mM}$ concentration range indicative of a process that is not impeded by the PIM-EA-TB film coating. This behaviour confirms that the silver microparticles are active when immobilised on the glassy carbon electrode surface.

When investigating the voltammetric response in different types of electrolyte media but at constant $\mathrm{pH}$, significant changes are observed. In aqueous $0.01 \mathrm{M} \mathrm{NaOH}$ at $\mathrm{pH} 12$, only a small oxidation response is seen possibly associated with the formation of an oxide coating (see Fig. 5a). During the reverse potential sweep, very sharp and stochastic reduction peaks are observed. In aqueous phosphate buffer at $\mathrm{pH} 12$, a lower concentration (10 $\mathrm{mM}$ buffer) appears to lead to enhanced (continued) dissolution during oxidation. At a much higher buffer concentration ( $500 \mathrm{mM}$ buffer), oxidation currents are significantly lowered. At an intermediate concentration of $100 \mathrm{mM}$ phosphate buffer, a significant oxidation peak is observed at $0.3 \mathrm{~V}$ vs. SCE with a corresponding reduction peak at $-0.1 \mathrm{~V}$ vs. SCE. The effect of the phosphate buffer concentration on the voltammetric peak suggests a maximised response at $0.1 \mathrm{M}$ concentration mirroring the results reported recently for other types of silver/glassy carbon contacts [19]. The underlying reasons are likely to be associated with a trade-off between electrolyte conductivity and solubility and will need further study.
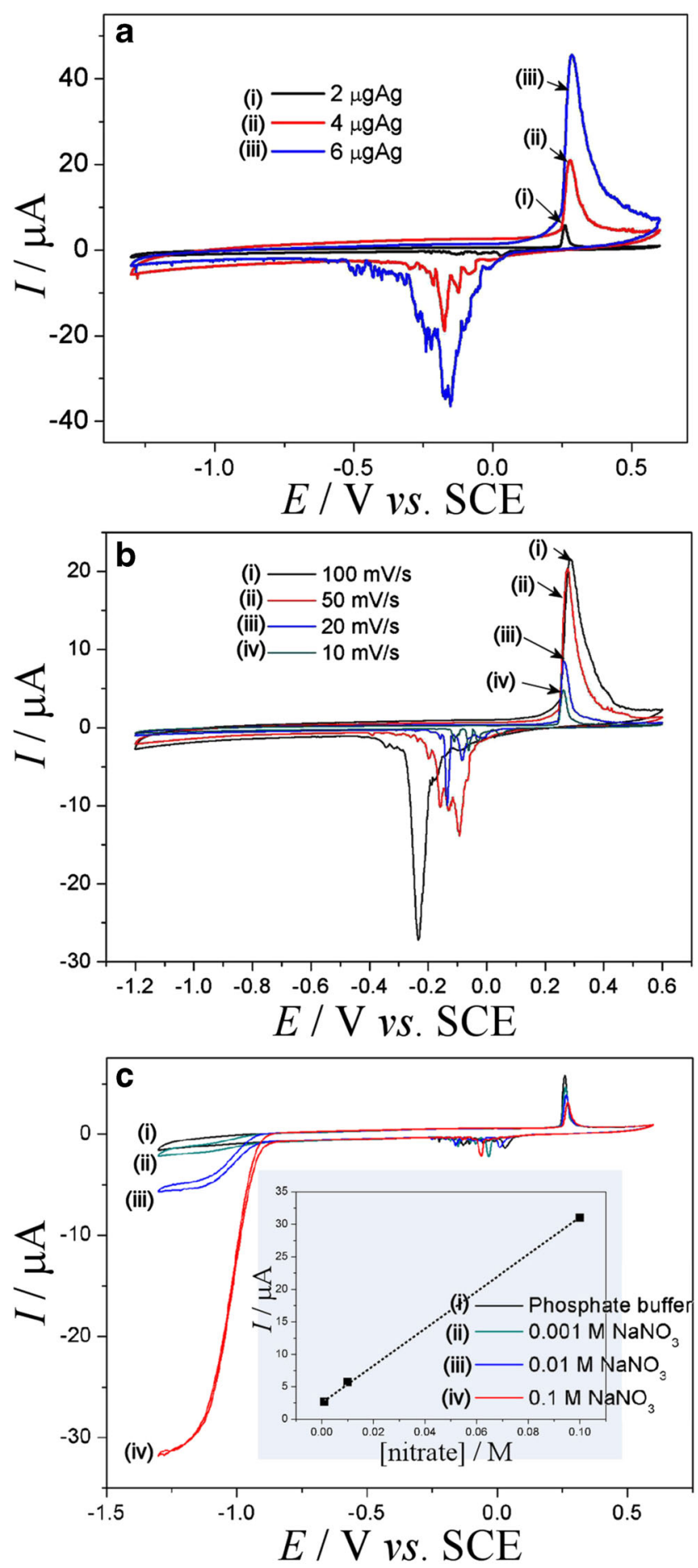

Fig. 4 a Cyclic voltammograms (scan rate $20 \mathrm{mV} \mathrm{s}^{-1}$ ) for 2, 4, or $6 \mu \mathrm{g}$ micro-silver deposited onto glassy carbon coated with $4 \mu \mathrm{g}$ PIM and immersed into aqueous $0.1 \mathrm{M}$ PBS $\mathrm{pH} 12$. b As above for $2 \mu \mathrm{g}$ microsilver at different scan rates. c Cyclic voltammograms (scan rate $20 \mathrm{mV} \mathrm{s}^{-1}$ ) for $2 \mu \mathrm{g}$ micro-silver in $0.1 \mathrm{M}$ PBS pH 12 with (i) 0 , (ii) 1 , (iii) 10 , and (iv) $100 \mathrm{mM} \mathrm{NaNO}_{3}$ added 

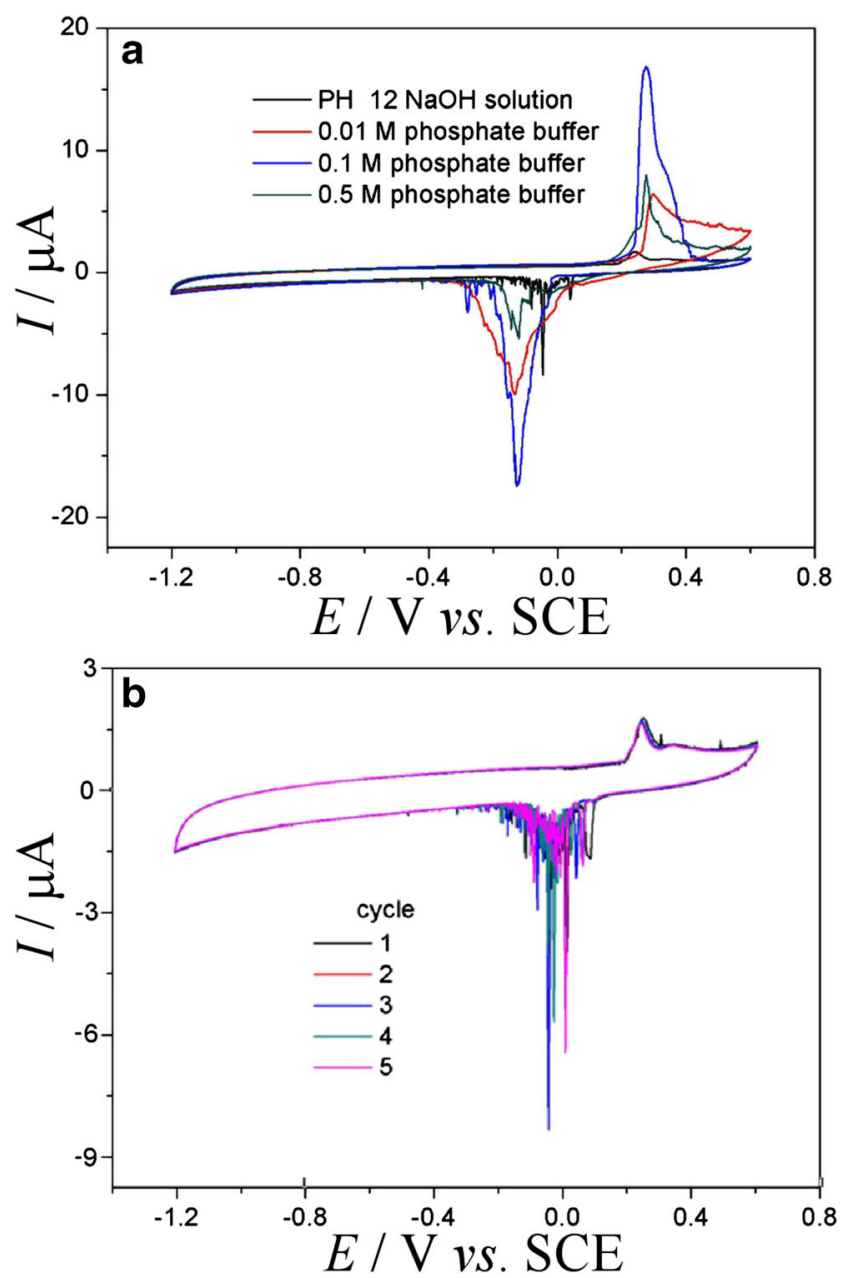

Fig. 5 a Cyclic voltammogram (scan rate $50 \mathrm{mV} \mathrm{s}^{-1}$ ) for $2 \mu \mathrm{g}$ microsilver deposited onto glassy carbon coated with $4 \mu \mathrm{g}$ PIM and immersed into aqueous $\mathrm{pH} 12$ solution as a function of ionic strength. b Multi-cycle experiment (scan rate $50 \mathrm{mVs}^{-1}$ ) for $\mathrm{pH} 12 \mathrm{NaOH}$ solution

For all concentrations of phosphate buffer, significant randomness in the reduction signal is observed. This is most clearly seen for experiments in $0.01 \mathrm{M} \mathrm{NaOH}$. Figure $5 \mathrm{~b}$ shows a multi-cycle voltammetric experiment performed in $\mathrm{pH} 12 \mathrm{NaOH}$ solution showing the stochastic nature of the reduction current peaks, which occur around $0.0 \mathrm{~V}$ vs. SCE and with an average charge complementary to that observed for the oxidation peak, however, in short "bursts" which may be linked to individual particles or regions on the electrode surface "re-connecting" to the silver microparticles. The trigger responsible for these processes could be associated at least in part with a density fluctuation in the liquid phase adjacent to the electrode surface or "Brownian activation".

This type of phenomenon is closely linked to Brownian motion and the associated diffusional transport in the liquid phase. Brownian motion [26] as proposed by Einstein and by von Smoluchowski [27] is induced by natural fluctuations in the density of the liquid, which are comparable to the more collective fluctuations caused by lattice phonons in solid materials. Artificial Brownian motors [28] are of interest in nanoscale systems that exploit these density fluctuations. Brownian motion of objects at liquid/solid interfaces can affect the rate of physical processes such as electron transfer, but these effects require micron-sized particles to become apparent. The idea of "Brownian activation" has been postulated previously for example for the inter-nanoparticle electron transfer within hybrid films of redox active $\mathrm{TiO}_{2}$ nanoparticles [29]. Related effects of Brownian motion at liquid/solid interfaces may also play a role in the voltammetry of "impact" processes [30, 31] where stochastic effects are assigned to bulk transport (motion) rather than to surface processes (activation).

For cyclic voltammograms shown in Fig. 5a, nucleation processes are believed to be responsible for the sharp oxidation peak observed during the oxidation of silver microparticles in the presence of phosphate buffer. In contrast, the reduction is governed by a stochastic process with multiple events that occur of a period of time. When scanning the potential of the electrode more quickly, these current responses distribute to more negative potentials indicative either (i) of irreversible electron transfer (microscopic) and/or (ii) irreversible activation of microparticles (macroscopic). The stochastic nature of "Brownian activation" is suggested to be associated with these processes but further investigation of the mechanism will be necessary.

\section{Summary and conclusion}

Silver microparticle voltammetry experiments were performed with the help of an intrinsically microporous polymer film coating. The key findings are as follows:

(A) an improved voltammetric response for silver microparticles was observed when deposits at the electrode surface are mechanically stabilised against loss and dislodgment with the PIM-EA-TB coating and

(B) the voltammetric characteristics (apart from the magnitude of the current) for the silver microparticles immersed in aqueous electrolyte media at $\mathrm{pH} 12$ are not affected by the PIM-EA-TB polymer coating for the oxidation of silver, the back reduction to silver metal, and for the catalytic reduction of nitrate to nitrite; the PIM-EA-TB film is sufficiently permeable for both cations and anions under these conditions;

(C) for the $\operatorname{Ag}(\mathrm{I} / 0)$ reduction, the stochastic nature of voltammetric current responses suggests that natural density fluctuations at the glassy carbon | silver microparticle interface (Brownian activation) could be the trigger to voltammetric responses.

These are preliminary findings and further work and optimisation of processes and peak appearances will be possible adjusting parameters such as ionic strength, $\mathrm{pH}$, and phosphate concentration. Potential applications of the stochastic 
voltammetric response may be in electroanalysis (e.g. when traces of chemical species could trigger or suppress the current spikes). The beneficial application of PIM-EA-TB as an intrinsically microporous coating in microparticle voltammetry could be of interest in a wider range of electroanalytical applications and in particular in electrocatalysis with immobilised microparticle catalysts.

Acknowledgement D.H. thanks the Royal Society for a Newton Fellowship. F.M. and N.B.M. thank the Leverhulme Foundation for the financial support (RPG-2014-308). E.R. thanks the Estonian Research Council (Grant PUT431) and the European Regional Development Fund project TK134 (TAR16019) for the financial support.

Open Access This article is distributed under the terms of the Creative Commons Attribution 4.0 International License (http:// creativecommons.org/licenses/by/4.0/), which permits unrestricted use, distribution, and reproduction in any medium, provided you give appropriate credit to the original author(s) and the source, provide a link to the Creative Commons license, and indicate if changes were made.

\section{References}

1. Scholz F, Meyer B (1998) Voltammetry of solid microparticles immobilized on electrode surfaces. Electroanal Chem 20:1-86

2. Bond AM, Marken F, Hill E, Compton RG, Hügel (1997) The electrochemical reduction of indigo dissolved in organic solvents and as a solid mechanically attached to a basalt plane pyrolytic graphite electrode immersed in aqueous electrolyte solution. J Chem Soc Perkin Trans 2:1735-1742

3. Scholz F, Lange B (1992) Abrasive stripping voltammetry - an electrochemical solid-state spectroscopy or wide applicability. TRAC-Trends Anal Chem 11:359-367

4. Domenech A, Domenech-Carbo MT, Pasies T, Bouzas MC (2011) Application of modified tafel analysis to the identification of corrosion products on archaeological metals using voltammetry of microparticles. Electroanalysis 23:2803-2812

5. Cepria G, Abadias O, Perez-Arantegui J, Castillo JR (2001) Electrochemical behavior of silver-copper alloys in voltammetry of microparticles: a simple method for screening purposes. Electroanalysis 13:477-483

6. Eloul S, Kätelhön E, Batchelor-McAuley C, Tschulik K, Compton RG (2015) Diffusional impacts of nanoparticles on microdisc and microwire electrodes: the limit of detection and first passage statistics. J Electroanal Chem 755:136-142

7. Sokolov SV, Bartlett TR, Fair P, Fletcher S, Compton RG (2016) Femtomolar detection of silver nanoparticles by flow-enhanced direct-impact voltammetry at a microelectrode array. Anal Chem 88 : 8908-8912

8. Plowman BJ, Young NP, Batchelor-McAuley C, Compton RG (2016) Nanorod aspect ratios determined by the nano-impact technique. Angew Chem Int Ed 55:7002-7005

9. Kätelhön E, Feng A, Cheng W, Eloul S, Batchelor-McAuley C, Compton RG (2016) Understanding nano-impact current spikes: electrochemical doping of impacting nanoparticles. J Phys Chem C 120:17029-17034

10. Bartlett TR, Sokolov SV, Compton RG (2015) Electrochemical nanoparticle sizing via nano-impacts: how large a nanoparticle can be measured? Chem Open 4:600-605

11. Gorle DB, Karuppusamy S, Kulandainathan MA, He DP, Marken F (2016) An investigation of electrochemical contact processes for silver-wire|glassy carbon and silver-coated cotton textile | glassy carbon. New J Chem 40:2814-2822

12. Xia FJ, Pan M, Mu SC, Malpass-Evans R, Carta M, McKeown NB, Attard GA, Brew A, Morgan DJ, Marken F (2014) Polymers of intrinsic microporosity in electrocatalysis: novel pore rigidity effects and lamella palladium growth. Electrochim Acta 128:3-9

13. Rong YY, Malpass-Evans R, Carta M, McKeown NB, Attard GA, Marken F (2014) Intrinsically porous polymer protects catalytic gold particles for enzymeless glucose oxidation. Electroanalysis 26:904-909

14. He DP, Rong YY, Kou ZK, Mu SC, Peng T, Malpass-Evans R, Carta M, McKeown NB, Marken F (2015) Intrinsically microporous polymer slows down fuel cell catalyst corrosion. Electrochem Commun 59:72-76

15. Madrid E, Rong YY, Carta M, McKeown NB, Malpass-Evans R, Attard GA, Clarke TJ, Taylor SH, Long YT, Marken F (2014) Metastable ionic diodes derived from an amine-based polymer of intrinsic microporosity. Angew Chem Int Ed 53:10751-10754

16. Rong YY, Malpass-Evans R, Carta M, McKeown NB, Attard GA, Marken F (2014) High density heterogenisation of molecular electrocatalysts in a rigid intrinsically microporous polymer. Electrochem Commun 46:26-29

17. Carta M, Malpass-Evans R, Croad M, Rogan Y, Jansen JC, Bernardo P, Bazzarelli F, McKeown NB (2013) An efficient polymer molecular sieve for membrane gas separations. Science 339:303-307

18. Rauwel E, Galeckas A, Rauwel P, Fjellvåg H (2012) Unusual photoluminescence of $\mathrm{CaHfO} 3$ and $\mathrm{SrHfO} 3$ nanoparticles. Adv Func Mater 22:1174-1179

19. Rauwel E, Galeckas A, Rauwel P, Sunding MF, Fjellvåg H (2011) Precursordependent blue-green photoluminescence emission of ZnO nanoparticles. J Phys Chem C 115:25227-25233

20. Küünal S, Kutti S, Rauwel P, Guha M, Wragg D, Rauwel E (2016) Biocidal properties study of silver nanoparticles used for application in green housing. Internat Nano Lett 6:191-197

21. Küünal S, Kutti S, Rauwel P, Wragg D, Hussainova I, Rauwel E (2016) New methodology for the antifungal testing of surfactantfree silver metal nanoparticles for applications in green housing, key engineer. Mater 674:133-138

22. Hickling A, Taylor D (1947) The anodic behaviour of metals.4. Silver. Disc. Faraday Soc 1:277-285

23. Wiberg E, Wiberg N, Holleman AF (2001) Inorganic chemistry. Academic Press, London, p 721

24. Gross AJ, Holmes S, Dale SEC, Smallwood MJ, Green SJ, Winlove CP, Benjamin N, Winyard PG, Marken F (2015) Nitrite/nitrate detection in serum based on dualplate generator-collector currents in a microtrench. Talanta 131:228-235

25. Fajerwerg K, Ynam V, Chaudret B, Garcon V, Thouron D, Comtat M (2010) An original nitrate sensor based on silver nanoparticles electrodeposited on a gold electrode. Electrochem Commun 12:1439-1441

26. Selmeczi D, Tolic-Norrelykke SF, Schaffer E, Hagedorn PH, Mosler S, Berg-Sorensen K, Larsen NB, Flyvbjerg H (2007) Brownian motion after Einstein and Smoluchowski: some new applications and new experiments. Acta Phys Pol B 38:2407-2431

27. von Smoluchowski M (1906) The kinetic theory of Brownian molecular motion and suspensions. Ann Phys 21:756-780

28. Hanggi P, Marchesoni F (2009) Artificial Brownian motors: controlling transport on the nanoscale. Rev Modern Phys 81:387-442

29. Rassaei L, Herrmann M, Gordeev SN, Marken F (2012) Interparticle charge transfer in TiO2-phytate films: generator-collector gold-gold junction transients. J Electroanal Chem 686:32-37

30. Kätelhön E, Tanner EEL, Batchelor-McAuley C, Compton RG (2016) Destructive nano-impacts: what information can be extracted from spike shapes? Electrochim Acta 199:297-304

31. Cutress IJ, Rees NV, Zhou YG, Compton RG (2011) Nanoparticleelectrode collision processes: investigating the contact time required for the diffusion controlled monolayer underpotential deposition on impacting nanoparticles. Chem Phys Lett 514:58-61 